\title{
Need for national surveillance for hospital infections
}

Hospitals should test and track Clostridium difficile, and provincial governments should organize infection control networks that could publish hospital infection rates, says a leading infectious diseases expert.

"I sit here in Kingston not knowing what's going on in Toronto or Ottawa," says Dr. Dick Zoutman, medical director of infection prevention and control at the South Eastern Ontario Health Sciences Centre in Kingston, Ont.

Outbreaks of $C$. difficile are occurring in Montréal and Calgary hospitals; at least 79 people $\varnothing$ have died in Montréal and 4 in Calgary after contracting the infection in the last 18 months (see page 19).

Hospitals are not required to report nosocomial infections like C. difficile to public health authorities, and neither provincial authorities nor Health Canada are tracking the infection.

There is a "chasm between public health and public health in the hospital," says Shirley Paton, Health Canada's chief of nosocomial and occupational infection. Canada's new public health agency will examine the problem, she says. "It would be useful to have national data."

In some regions, authorities are trying to bridge the chasm. Montréal public health, for example, recently provided resources for surveillance in area hospitals, says Dr. Mark Miller of the Jewish General Hospital. Miller's group is looking at the 6-month rate and severity of $C$. difficile. Results are slotted for release in late July.

But province-wide surveillance is still lacking. As chair of the Ontario SARS Scientific Advisory Committee, Zoutman recommended Ontario create a Centre for Infectious Diseases. More recently, the Ontario Expert Panel on Infectious Diseases recommended creating regional communicable disease and infection control networks.

Increasing the availability of infection data would allow physicians to compare their infection rates to those occurring in other hospitals, says Zoutman. Health Canada already provides a similar service for physicians during influenza season.

In the US, both Pennsylvania and Illinois have passed legislation requiring hospitals to report hospital infections. Three other states - Missouri, Florida and California — have similar bills wending their way through the legislative process or awaiting a governor's signature. Laura Eggertson and Barbara Sibbald, CMAJ

\section{International Health}

\section{Global diet and exercise plan approved}

Food industry lobbyists were outflanked by the World Health

$\approx$ Organization when delegates at the World Health Assembly in Geneva this May endorsed the world's first global strategy on diet and exercise.

The strategy, branded a "landmark achievement in global public health policy" by

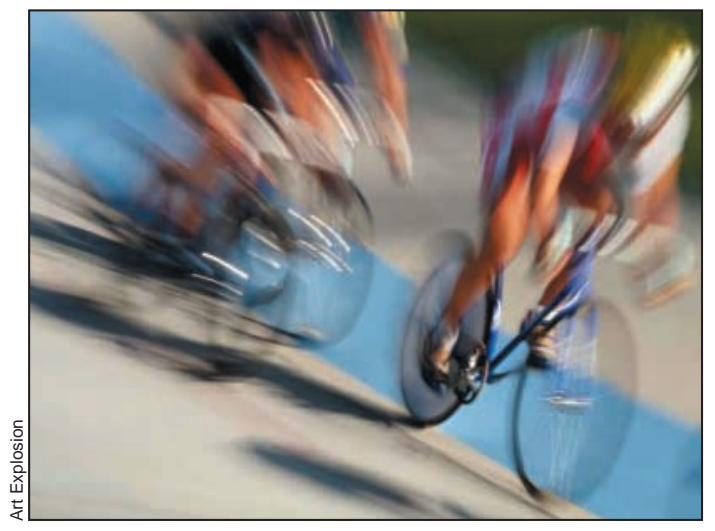

Breaking the cycle of inactivity and poor eating.
WHO Assistant Director General Dr. Catherine Le GalèsCamus, offers detailed guidance for national governments on promoting healthy eating and exercise (www.who.int).

Controversially, it stresses the need to limit the consumption of saturated fats, transfatty acids, salt and sugars ( $C M A 7$ 2003;168[12]:1585). It also says food marketing to children should be curbed.

The small WHO team responsible for the strategy spent 2 years in consultations but still faced fierce opposition.

The sugar lobby and the soft drink manufacturers set out to convince sugar-producing countries that the strategy should be shelved for at least a year.

Spokesperson for the International Obesity Task Force Neville Rigby said the adoption of the plan is the climax of re- cent developments in the fight against obesity, particularly in North America.

"There is a bushfire spreading across the USA. Consumers are getting angry ... they can see what is happening to their children."

How quickly national governments now act depends partly on the lobbying efforts of the private sector. Rigby contrasted the lobbying from the sugar industry with that of companies who are recognizing that they have to be part of the solution.

In a key move just days before the assembly debate, the Grocery Manufacturers of America and the Confederation of the Food and Drink Industries of the European Union announced they backed the WHO strategy. - Colin Meek, Wester Ross, Scotland 